\title{
Two Cases of Myelodysplastic Syndrome with Extramedullary Polyclonal Plasma Cell Proliferation and Autoantibody Production: Possible Role of Soluble Fas Antigen for Production of Excessive Self-Reactive B Cells
}

\author{
Kensaku Katsuki, Kenji Shinohara, Naoko Kameda, Tetsuya Yamada, Koumei Takeda and Toshiaki Kamei
}

\begin{abstract}
Two cases of myelodyspalstic syndrome (MDS) with extramedullary polyclonal plasma cell proliferation and autoantibody production are reported. These cases, which showed leukemic change of refractory anemia with excess of blast (RAEB), developed lymph node swelling and muscle abscess; both were infiltrated mainly with plasma cells, without preceding infection. The proliferation of plasma cells was polyclonal and was proven by negative rearrangement of immunoglobulin heavy chain gene or polyclonal staining of immunoglobulin light chains. These patients showed polyclonal gammopathy and autoantibody production such as positive antinuclear factor and direct antiglobulin test. As was observed in one of the present cases, and as we reported previously, the elevated level of soluble Fas antigen in MDS patients, and its inhibition of apoptotic signaling may be responsible for the excessive accumulation of self-reactive $B$ cells, resulting in these clinical manifestations.

(Internal Medicine 37: 973-977, 1998)
\end{abstract}

Key words: refractory anemia with excess of blast (RAEB), lymphadenopathy, muscle abscess, gammopathy, apoptosis

\section{Introduction}

In myelodysplastic syndrome (MDS), hematopoietic stem cells demonstrate increased expression of Fas antigen, and these cells undergo programmed cell death, apoptosis, resulting in cytopenia (1). In MDS, the coexistence of leukemia with lymphoma or plasma cell neoplasms is rarely observed and these are thought to arise from common pluripotent stem cells (2).

Immunological abnormalities are observed in some MDS patients, and monoclonal gammopathy or polyclonal increase in immunoglobulins with production of autoantibodies is observed (3). The pathogenesis of polyclonal gammopathy with autoantibody production is unknown.

There are experimental mice models of lymphocyte proliferative (lpr) syndrome that demonstrate recessive mutation of lpr gene which encodes Fas antigen (4), or generalized lymphoproliferative disease (gld) that have a mutation of the Fas ligand encoding gene (5), as well as autoimmune lymphoproliferative syndrome (ALPS) in humans, which shows mutations in the Fas antigen encoding gene $(6,7)$. These diseases have clinical characteristics of generalized lymphadenopathy and autoantibody production resembling autoimmune disease resulting from the accumulation of CD4- CD8- (double negative) $\mathrm{T}$ cells (8). These studies demonstrated that $\mathrm{T}$ cell precursors arise in the bone marrow and mature, then $\mathrm{T}$ cells recognizing self-antigens are destroyed during maturation by apoptosis in the thymus (4) or by activation-induced cell death in the periphery (8), and thus maintain tolerance to self-antigens. Under these pathologic circumstances, self-reactive T (4$9)$ and B cells $(4,10)$ escape from elimination by apoptosis and activation-induced cell death during maturation and result in the accumulation of self-reactive $\mathrm{T}$ and $\mathrm{B}$ cells by functional defects in the Fas-Fas ligand-mediated apoptosis.

The soluble form of Fas antigen inhibits the reaction of FasFas ligand in a dose-dependent manner (1). The administration of soluble Fas antigen in mice produces a SLE-like autoimmune disease (11).

We encountered two cases of MDS with extramedullary polyclonal plasma cell proliferation and autoantibody produc-

From the Division of Hematology, Department of Medicine and Department of Pathology, Yamaguchi Prefecture Central Hospital, Hofu

Received for publication February 23, 1998; Accepted for publication August 18, 1998

Reprint requests should be addressed to Dr. Kenji Shinohara, the Division of Hematology, Department of Medicine, Yamaguchi Prefecture Central Hospital, Hofu 747-0065 
tion. The clinical manifestations in our patients resembled those in lpr/gld mice model and in human ALPS.

We previously demonstrated elevated levels of soluble Fas antigen in MDS patients (12). In the present cases, the elevated soluble Fas antigen is likely responsible for these clinical manifestations impairing Fas-mediated apoptosis resulting in accumulation of self-reactive B cells as lymph node swelling and muscle abscess, and autoantibody production in these MDS patients.

\section{Patients}

\section{Case 1}

A 71-year-old man was diagnosed with refractory anemia with excess of blast (RAEB) in September 1995. The patient complained of fever and a painful muscle abscess measuring 10 $\mathrm{cm}$ in diameter on the left thigh in January 1997. Laboratory findings on admission are shown in Table 1. RAEB had transformed to leukemia and an increase in plasma cells was observed on bone marrow aspiration smear. Serum immunoglobulins increased polyclonally, and antinuclear antibody and direct antiglobulin test were positive. The biopsy specimen of the abscess revealed infiltration mainly by mature plasma cells (Fig. 1). Bacteriological culture of the secretions from the abscess was negative, including tests for tuberculosis bacilli. The abscess improved one month later without any treatment. The patient complained of peritonsillar abscess and cervical lymph node swelling measuring $2-5 \mathrm{~cm}$ in diameter and inguinal lymph node swelling to $2 \mathrm{~cm}$ in diameter in April. A biopsy specimen of the lymph node also revealed infiltration mainly of mature plasma cells (Fig. 2). Chromosome analysis of the lymph node specimen was normal and flow cytometry analysis of lymphocyte subsets did not reveal any particular change compared with those in the normal control (Table 2), and there was no rearrangement of the immunoglobulin heavy chain gene (data not shown). The patient died of pneumonia in

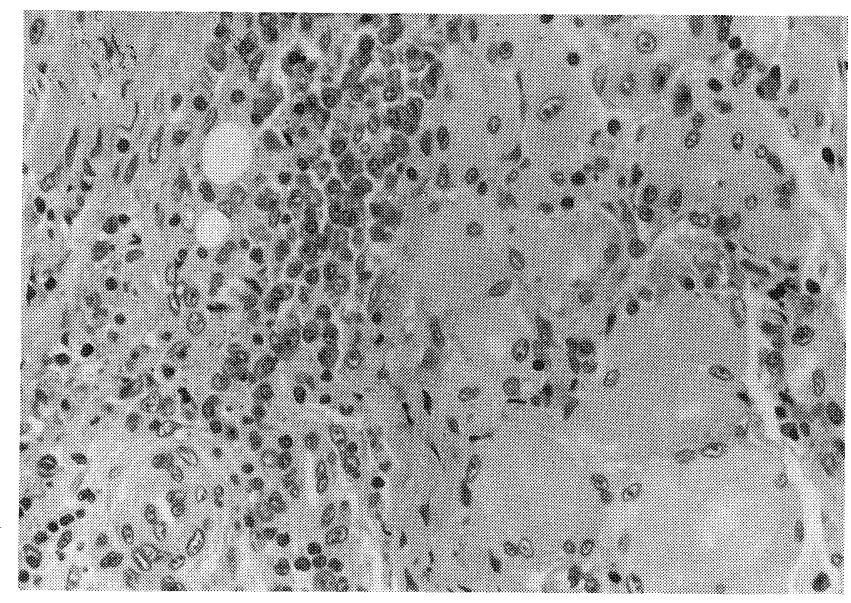

Figure 1. Microscopic findings of the muscle abscess showing infiltration mainly by mature plasma cells in case 1 (HE stain, $\times 50)$.
Table 1. Laboratory Examination of the Patients on Admission

\begin{tabular}{|c|c|c|}
\hline & Case 1 & Case 2 \\
\hline \multicolumn{3}{|l|}{ CBC: } \\
\hline Red blood cell $\left(\times 10^{4} / \mu 1\right)$ & 233 & 176 \\
\hline Hematocrit $(\%)$ & 23.1 & 16.1 \\
\hline Hemoglobin (g/dl) & 6.1 & 5.3 \\
\hline Platelet $\left(\times 10^{4} / \mu 1\right)$ & 17.3 & 5.1 \\
\hline White blood cell $(/ \mu \mathrm{l})$ & 4,500 & 2,000 \\
\hline N Myelocyte (\%) & 2 & 1 \\
\hline N Metamyelocyte (\%) & 2 & 1 \\
\hline N Band (\%) & 26 & 2 \\
\hline N Segmented $(\%)$ & 25 & 39 \\
\hline Basophil (\%) & 1 & \\
\hline Lymphocyte (\%) & 42 & 56 \\
\hline \multicolumn{3}{|l|}{ Bone Marrow: } \\
\hline Cellularity & marked hyper & hyper \\
\hline $\mathrm{M} / \mathrm{E}$ & 2.13 & 2.13 \\
\hline Myeloblast (\%) & 34.2 & 14.4 \\
\hline Promyelocyte (\%) & 6.4 & 3.2 \\
\hline N Myelocyte (\%) & 17.6 & 30.4 \\
\hline N Metamyelocyte (\%) & 3.2 & 18.8 \\
\hline N Band (\%) & 2.6 & 11.8 \\
\hline N Segmented (\%) & 0.8 & 7.2 \\
\hline Lymphocyte (\%) & 2.8 & 4.0 \\
\hline Plasma cell $(\%)$ & 2.0 & 2.0 \\
\hline \multicolumn{3}{|l|}{ Erythroblast } \\
\hline Basophilic (\%) & & 0.2 \\
\hline Polychromatophilic (\%) & & 0.2 \\
\hline Orthochromatic (\%) & 30.4 & 7.8 \\
\hline Chromosome: & $46 X Y$ & $46 X Y$ \\
\hline \multicolumn{3}{|l|}{ Chemistry: } \\
\hline Total Bilirubin (mg/dl) & 2.4 & 0.5 \\
\hline Albumin $(\mathrm{g} / \mathrm{dl})$ & 2.4 & 2.7 \\
\hline Globulin $(\mathrm{g} / \mathrm{dl})$ & 4.6 & 2.1 \\
\hline Aspartate aminotransferase (IU/l) & 74 & 15 \\
\hline Alanine aminotransferase (IU/l) & 79 & 11 \\
\hline Lactate dehydrogenase (IU/l) & 1,071 & 299 \\
\hline$\gamma$-glutamyltranspeptidase (IU/l) & 15 & 15 \\
\hline Alk-P (IU/l) & 189 & 99 \\
\hline Blood Sugar (mg/dl) & 90 & 115 \\
\hline Cholesterol (mg/dl) & 73 & 111 \\
\hline Blood urea nitrogen (mg/dl) & 10.2 & 19.0 \\
\hline Creatinine (mg/dl) & 0.6 & 0.7 \\
\hline C-reactive protein $(\mathrm{mg} / \mathrm{dl})$ & 6.4 & 1.9 \\
\hline \multicolumn{3}{|l|}{ Immunoglobulin } \\
\hline $\mathrm{G}(\mathrm{mg} / \mathrm{dl})$ & 3,920 & 1,590 \\
\hline $\mathrm{A}(\mathrm{mg} / \mathrm{dl})$ & 1,120 & 402 \\
\hline $\mathrm{M}(\mathrm{mg} / \mathrm{dl})$ & 152 & 62 \\
\hline \multicolumn{3}{|l|}{ Serology: } \\
\hline Antinuclear Factor $(<40)$ & 40 & 40 \\
\hline Anti-DNA Test $(\mathrm{IU} / \mathrm{ml},<7)$ & 6.9 & 5.0 \\
\hline Direct Antiglobulin Test & $(+)$ & $(-)$ \\
\hline
\end{tabular}




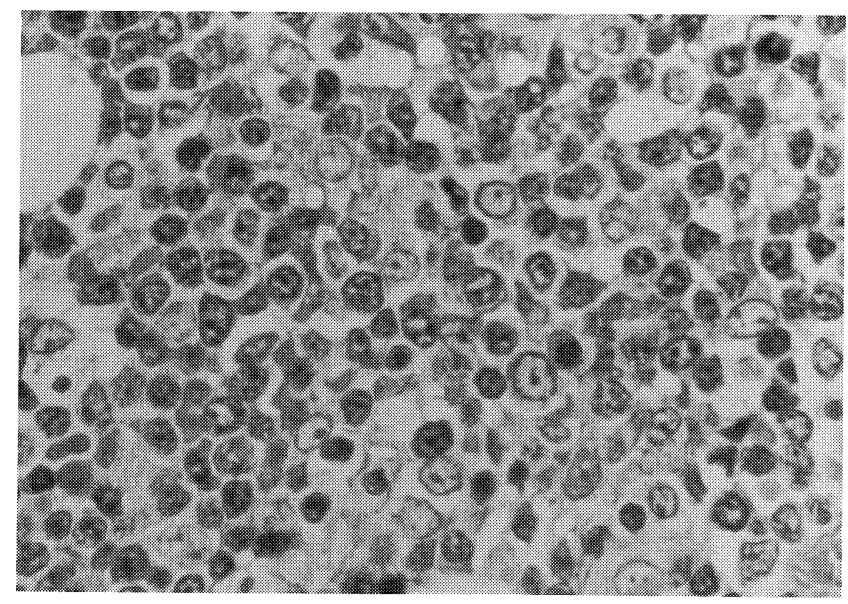

Figure 2. Microscopic findings of the biopsied cervical lymph node showing infiltration mainly by mature plasma cells in case 1 (HE stain, $\times 200)$.

Table 2. Flow Cytometry Analysis of the Biopsied Lymph Node Cells in Case 1 and Case 2

\begin{tabular}{lccr}
\hline & $\begin{array}{c}\text { Case 1 } \\
(\%)\end{array}$ & $\begin{array}{c}\text { Case 2 } \\
(\%)\end{array}$ & $\begin{array}{c}\text { Control } \\
(\%)\end{array}$ \\
\hline CD1 & \multicolumn{1}{c}{ (\%) } & 0.2 & 0.1 \\
CD2 & 51.2 & 57.1 & 49.0 \\
CD3 & 46.0 & 56.3 & 45.0 \\
CD4 & 38.0 & 42.5 & 26.3 \\
CD5 & 50.7 & 57.2 & 45.1 \\
CD7 & 47.1 & 42.0 & 41.7 \\
CD8 & 7.7 & 20.6 & 19.8 \\
CD10 & 0.5 & 1.0 & 10.6 \\
CD13 & 1.4 & 1.0 & 0.4 \\
CD14 & 0.8 & 0.7 & 0.4 \\
CD19 & 41.7 & 36.9 & 58.5 \\
CD20 & 37.5 & 28.7 & 61.0 \\
CD33 & 1.2 & 0.4 & 0.5 \\
HLA-DR & 53.4 & 51.6 & 70.7 \\
CD95 & 9.7 & 13.1 & 10.4 \\
\hline
\end{tabular}

July.

\section{Case 2}

An 83-year-old man was diagnosed as RAEB in October 1996. The patient complained of fever and painful swelling of axillary and inguinal lymph nodes, which measured $1-2 \mathrm{~cm}$ in diameter in February 1997. Laboratory findings on admission are shown in Table 1. Bone marrow aspiration smear revealed an increase in plasma cells. Serum immunoglobulins were normal and antinuclear factor was positive. The biopsied specimen of lymph node revealed mainly mature plasma cells (Fig. 3 ). The staining of immunoglobulin light chains, $\kappa$ and $\lambda$, were both positive (data not shown). Chromosomal analysis of the lymph node specimen was normal and flow cytometry analysis

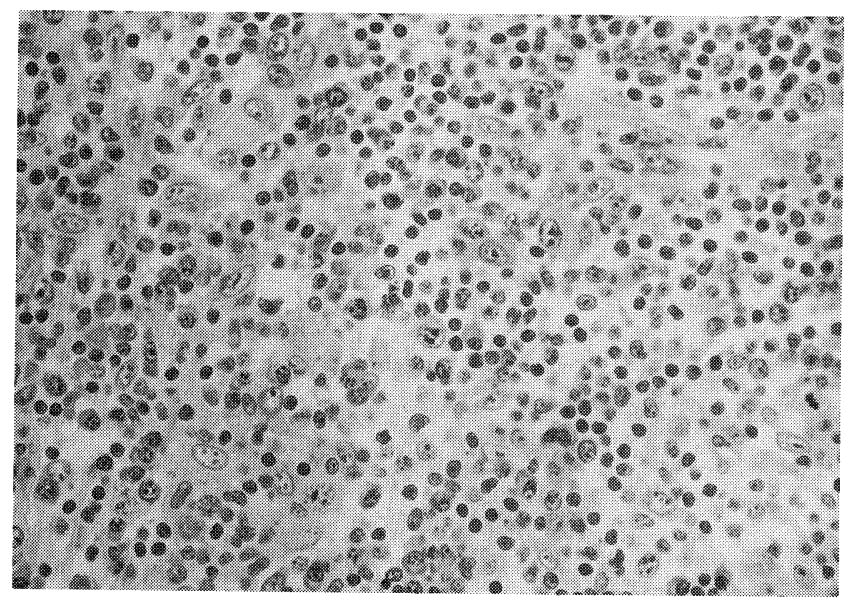

Figure 3. Microscopic findings of the biopsied inguinal lymph node showing infiltration mainly by mature plasma cells in case 2 (HE stain, $\times 50$ ). The staining of immunoglobulin light chains, $\kappa$ and $\lambda$, were both positive (data not shown).

of lymphocyte subsets did not reveal any particular change compared with those in the normal control (Table 2). There was no rearrangement of the immunoglobulin heavy chain gene (data not shown). The plasma level of soluble Fas antigen was $4.97 \mathrm{ng} / \mathrm{ml}$ (normal value <2.26). The lymph nodes swelling disappeared one month later without any treatment, and level of soluble Fas antigen dropped to $2.70 \mathrm{ng} / \mathrm{ml}$.

\section{Discussion}

Clonal evolution of the hematopoietic system simultaneous with that of the lymphopoietic system is observed in MDS (2). Regarding serum immunoglobulins, monoclonal gammopathy was observed in $12.5 \%$ of patients, $32 \%$ had a polyclonal increase in immunoglobulins and $19 \%$ had low levels of immunoglobulins (3). A polyclonal increase in serum immunoglobulins is frequently accompanied by autoantibody production such as antinuclear factor and direct antiglobulin test in all types of MDS (3).

The mechanism which determines the clonality of lymphoplasmocytic cells in MDS is unknown. Of female patients heterozygous for M27 $\beta$, only $22 \%$ demonstrated monoclonality of peripheral blood lymphocytes, and only $7 \%$ showed monoclonal rearrangement of CDR3 (13). Gerritsen et al studied clonality in patients with MDS associated with monosomy 7 using fluorescence in situ hybridization (FISH), and demonstrated that monosomy 7 did not affect the lymphoid subpopulation but was restricted to myeloid committed progenitor cells (14). Polyclonal gammopathy may result from non-specific stimulation of B-lymphocytes by antigens encountered during infection (15).

However, the massive lymphadenopathy and skin infiltration with plasma cells in the present patients, and the appearance of these manifestations without preceeding infectious episodes do not support the role of infection alone as the 


\section{KATSUKI et al}

pathogenic cause of these symptoms.

In MDS, inflammatory skin lesions of Sweet's syndrome showing characteristic neutrophil infiltration frequently occur (16). However, the skin lesion of our first patient differed from Sweet's syndrome in that it was infiltrated with mature plasma cells. The results also indicated abnormal proliferation, distribution and migration of plasma cells.

The clinical manifestations of our patients were similar to those of lpr/gld mice $(4,5)$ and ALPS $(6,7)$. Treatment of lpr mice with cyclosporin A markedly decreases immunological lesions such as arthritis and glomerulonephritis, however, it did not reduce the concentration of autoantibodies (17). These abnormalities of humoral immunity may be due in part to dysregulation of $\mathrm{T}$ cells, but may also stem from increased numbers of self-reactive B cells, which are intrinsically prone to produce autoantibodies and are not merely passive recipients of abnormal signs from aberrant $\mathrm{T}$ cells $(18,19)$. Thus, Fas defects may impair the homeostasis of multiple immune cell types to produce a complex immunoregulatory disorder.

The administration of soluble Fas antigen has a marked effect on lymphocytic development, and causes an increase in CD4- CD8- (double negative) as well as CD4+ and CD8+ (single positive) thymocytes and additionally an increase in spleen B cells, resulting in SLE-like manifestations in mice (11).

We previously demonstrated increased levels of soluble Fas antigen in MDS patients (12). The level was elevated in case 2 and decreased after lymph node swelling ameliorated, however, it was not measured in case 1. A similar study reported MDS patients with immunological abnormalities who exhibited higher levels of soluble Fas antigen than patients without immunological abnormalities (20). The levels of soluble Fas antigen were higher in patients with SLE than in patients with other autoimmune diseases and healthy subjects. Furthermore, the frequency of a positive serum soluble Fas antigen was much greater in patients with higher disease activity, and serial determination of the serum Fas antigen levels demonstrated their parallel changes with the disease activity (21). These findings supported the significance of soluble Fas antigen in the pathogenesis of autoimmune disease. In the present cases, the clinical manifestations including lymph node swelling and muscle abscess which was infiltrated mainly by plasma cells, and autoantibody production, were more likely caused by elevated soluble Fas antigen inducing impaired elimination of $\mathrm{B}$ cells for apoptosis resulting in excessive production of selfreactive $B$ cells. However, we did not detect any aberrant phenotypes of lymphocytes in the biopsied lymph nodes of these patients.

Interleukin-6 (IL-6) production is occasionally observed in the germinal centers of hyperplastic lymphoid follicles obtained from chronic inflammatory lymph nodes, and also in Castleman's disease (22). The effect of IL-6 on the clinical features in the present cases is unknown, since we did not measure the IL- 6 concentration in the serum. However, our cases were different from these disorders, since the characteristic clinical features appeared during the course of MDS without preceeding infectious episodes, and were also different from Castleman's disease regarding the pathological findings.

Mutations of Fas antigen or Fas ligand encoding genes had been observed in lpr/gld mice $(4,5)$ and in human ALPS $(6,7)$, however these analyses remain unsolved in the present patients.

\section{References}

1) Hatake $\mathrm{K}$, Tomizuka $\mathrm{H}$, Ikeda $\mathrm{M}$, et al. The presence of apoptosis in refractory anemia of myelodysplasia. in: Molecular Biology of Haematopoiesis. Abraham NG, Ed. Intercept, Andover, 1994, p. 122-133.

2) Copplestone JA, Mufti GJ, Hamblin TJ, Oscier DG. Immunological abnormalities in myelodysplastic syndromes. II. Coexistent lymphoid or plasma cell neoplasms: a report of 20 cases unrelated to chemotherapy. $\mathrm{Br}$ J Haematol 63: 149-169, 1986.

3) Mufti GJ, Figes A, Hamblin TJ, Oscier DG, Copplestone JA. Immunological abnormalities in myelodysplastic syndromes. I. Serum immunoglobulins and autoantibodies. Br J Haematol 63: 143-147, 1986.

4) Watanabe-Fukunaga R, Brannan CI, Copeland NG, Jenkins NA, Nagata S. Lymphoproliferation disorder in mice explained by defects in Fas antigen that mediates apoptosis. Nature 356: 314-317, 1992.

5) Takahashi T, Tanaka M, Brannan CI,etal.Generalized lymphoproliferative disease in mice, caused by a point mutation in the Fas ligand. Cell 76: 969-976, 1994.

6) Rieux-Laucat F, Le Deist F, Hivroz C, et al. Mutations in Fas associated with human lymphoproliferative syndrome and autoimmunity. Science 268: 1347-1349, 1995.

7) Fisher GH, Rosenberg FJ, Straus SE, et al. Dominant interfering Fas gene mutations impair apoptosis in a human autoimmune lymphoproliferative syndrome. Cell 81: 935-946, 1995.

8) Theofilopoulos AN, Dixon FJ. Murine models of systemic lupus erythematosus. Adv Immunol 37: 269-390, 1985.

9) Singer GG, Abbas AK. The Fas antigen is involved in peripheral but not thymic deletion of $\mathrm{T}$ lymphocytes in $\mathrm{T}$ cell receptor transgenic mice. Immunity 1: 365-371, 1994.

10) Rathmell JC, Goodnow CC. Effects of the lpr mutation on elimination and inactivation of self-reactive B cells. J Immunol 153: 2831-2842, 1994.

11) Cheng J, Zhou T, Liu C, et al. Protection from Fas-mediated apoptosis by a soluble form of the Fas molecule. Science 263: 1759-1762, 1994.

12) Shinohara K, Ayame H, Yoshida T. Increased levels of soluble Fas antigen in the plasma of the patients with refractory anemia. Int J Hematol 65: 413-414, 1997 (letter).

13) Culligan DJ, Cachia P, Whittaker J, Jacobs A, Padua RA. Clonal lymphocytes are detectable in only some cases of MDS. Br J Haematol 81: 346-352, 1992.

14) Gerritsen ER, Donohue J, Bauman J, et al. Clonal analysis of myelodysplastic syndrome: monosomy 7 is expressed in the myeloid lineage, but not in the lymphoid lineage as detected by fluorescent in situ hybridization. Blood 80: 217-224, 1992.

15) Osserman EH, Takatsuki K. Considerations regarding the pathogenesis of the plasmacytic dyscrasias. Series Haematologica 4: 28-49, 1965.

16) Cohen PR, Kurzrock R. Sweet'S syndrome and malignancy. Am J Med 82: 1220-1226, 1987.

17) Mountz JD, Smith HR, Wilder RL, Reeves JP, Steinberg AD. CS-A therapy in MRL-lpr/lpr mice: amelioration of immunopathology despite autoantibody production. J Immunol 138: 157-163, 1987.

18) Perkins DL, Glaser RM, Mahon CA, Michaelson J, Marshak-Rothstein A. Evidence for an intrinsic B cell defect in lpr/lpr mice apparent in neonatal chimeras. J Immunol 145: 549-555, 1990.

19) Sobel ES, Katagiri T, Katagiri K, Morris SC, Cohen PL, Eisenberg RA. An intrinsic $\mathrm{B}$ cell defect is required for the production of autoantibodies in the lpr model of murine systemic autoimmunity. J Exp Med 173: 1441 1449, 1991.

20) Okamoto T, Okada M, Kanamaru A, Kakishita E. Analysis of immunological abnormalities associated with myelodysplastic syndrome in reference to the producibility of the lymphocytes for IL- 6 and IL-10 and serum 


\section{MDS with Plasma Cell Proliferation}

soluble Fas level. Int J Hematol 65: 628, 1997 (Abstract).

21) Jodo S, Kobayashi S, Kayagaki N, et al. Serum levels of soluble Fas/APO1 (CD95) and its molecular structure in patients with systemic lupus erythematosus (SLE) and other autoimmune diseases. Clin Exp Immunol
107: 89-95, 1997.

22) Yoshizaki K, Matsuda T, Nishimoto N, et al. Pathogenic significance of interleukin-6 (IL-6/BSF-2) in Castleman's disease. Blood 74: 13601367, 1989. 